\title{
Lasiodiplodia sp. ME4-2, an endophytic fungus from the floral parts of Viscum coloratum, produces indole-3-carboxylic acid and other aromatic metabolites
}

\author{
Chao-Dong Qian ${ }^{\dagger}$, Yu-Hang Fư ${ }^{\dagger}$ Fu-Sheng Jiang, Zheng-Hong Xu, Dong-Qing Cheng, Bin Ding, Cheng-Xian Gao \\ and Zhi-Shan Ding ${ }^{*}$
}

\begin{abstract}
Background: Studies on endophytes, a relatively under-explored group of microorganisms, are currently popular amongst biologists and natural product researchers. A fungal strain (ME4-2) was isolated from flower samples of mistletoe (Viscum coloratum) during a screening program for endophytes. As limited information on floral endophytes is available, the aim of the present study is to characterise fungal endophytes using their secondary metabolites.

Results: ME4-2 grew well in both natural and basic synthetic media but produced no conidia. Sequence analysis of its internal transcribed spacer rDNA demonstrated that ME4-2 forms a distinct branch within the genus Lasiodiplodia and is closely related to L. pseudotheobromae. This floral endophyte was thus identified as Lasiodiplodia sp. based on its molecular biological characteristics. Five aromatic compounds, including cyclo-(Trp-Ala), indole-3-carboxylic acid (ICA), indole-3-carbaldehyde, mellein and 2-phenylethanol, were found in the culture. The structures of these compounds were determined using spectroscopic methods combined with gas chromatography. To the best of our knowledge, our work is the first to report isolation of these aromatic metabolites from a floral endophyte. Interestingly, ICA, a major secondary metabolite produced by ME4-2, seemed to be biosynthesized via an unusual pathway. Furthermore, our results indicate that the fungus ME4-2 is a potent producer of 2-phenylethanol, which is a common component of floral essential oils.
\end{abstract}

Conclusions: This study introduces a fungal strain producing several important aromatic metabolites with pharmaceutical or food applications and suggests that endophytic fungi isolated from plant flowers are promising natural sources of aromatic compounds.

Keywords: Lasiodiplodia sp, Floral endophytes, Mistletoe, Aromatic compounds

\section{Background}

Endophytes refer to microorganisms that asymptomatically colonise the internal tissues of plants for at least a part of their life cycle. Each plant on earth, from the arctic tundra to the tropics, has been estimated to contain at least one endophyte $[1,2]$. Fungi and bacteria are the most common microbes existing as endophytes and presumed to have originated from the external environment, although some endophytes are vertically transmitted to

\footnotetext{
* Correspondence: dzszitcm@163.com

${ }^{\dagger}$ Equal contributors

Zhejiang Chinese Medical University, Hangzhou, Zhejiang province, China
}

succeeding plant generations via seeds [1,3]. A number of these microorganisms have intimate interactions with their host plants and can promote plant growth as well as enhance host adaptation to biotic and abiotic stress factors $[2,4,5]$. In some cases, the beneficial effects of endophytes are exhibited through production of bioactive secondary metabolites, such as plant hormones (e.g., auxins and cytokinins), adenine ribosides and defence-related compounds [6-8].

Although endophytes were discovered as early as 1904, they did not receive significant attention until the isolation of taxol from an endophytic fungus Taxomyces andreanae 
in 1993 [9]. Endophytes have since then been shown to produce several other well-known and important plant-derived compounds, such as camptothecin [10], isocoumarin [11] and podophyllotoxin [12], amongst others [13-15]. Although Heinig et al. [16] re-examined and found no evidence of independent taxane biosynthesis in any of the endophytes associated with Taxus species in 2013, it is believed that endophytes will become alternative sources for pharmacologically important natural products from plants [15,17]. In addition, endophytes can also produce a wide range of novel natural compounds with various biological activities [13-15,18]. As a significantly untapped reservoir of functional metabolites, endophytes are fairly under-utilised [19]. As such, additional investigations are necessary to discover new endophytes with potential applications [15,20,21].

Mistletoe Viscum coloratum, a semi-parasitic evergreen dioecious shrub, is an important medicinal herb used in Traditional Chinese Medicine mainly for treating rheumatic arthralgia and foetal upset [22]. Although mistletoe and its active secondary metabolites have been widely studied [23-25], research on endophytes from this herb is virtually unavailable. Endophytic fungal communities in the semi-parasitic epiphyte $V$. album and its phorophyte Pinus sylvestris were recently compared and studied [26,27]; however, no Viscum endophyte was isolated and screened for active compounds. During a screening program for endophytic microbes hosted by $V$. coloratum, an endophytic fungus, ME4-2, was isolated from the floral parts of the plant. The aim of the present study is to characterise the floral endophyte together with its active compounds. The major metabolites produced by the strain are aromatic compounds, including cyclo-(Trp-Ala) (1), indole-3-carboxylic acid (ICA) (2), indole-3-carbaldehyde (3), mellein (4) and 2-phenylethanol (5) (Figure 1), all of which are valuable compounds for the pharmaceutical and food industries, as well as host close related metabolites.

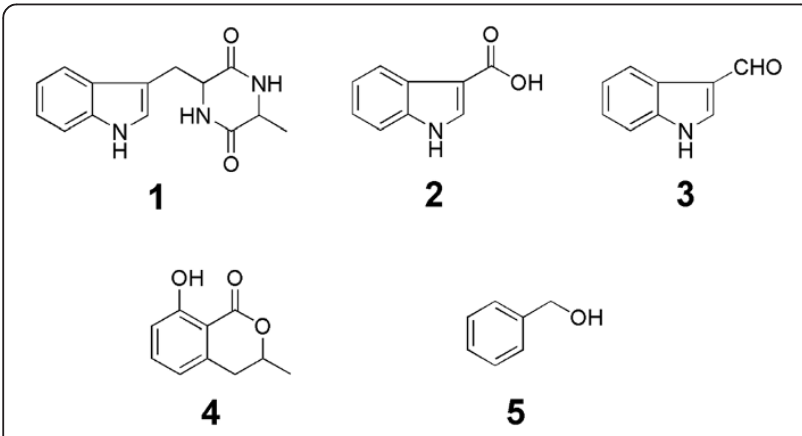

Figure 1 Compounds isolated from fermentation cultures of Lasiodiplodia sp. ME4-2. 1, cyclo-(Trp-Ala); 2, indole-3-carboxylic acid; 3, indole-3-carbaldehyde; 4, mellein; 5, 2-phenylethanol.

\section{Results and discussion}

\section{Identification of endophytic fungus ME4-2}

Six segments of each floral sample were placed on potato dextrose agar (PDA) and screened for the presence of endophytic fungi. ME4-2 was consistently isolated from all samples and selected for further studies. ME4-2 grew well on PDA and Czapek's media. Cultures were initially white with moderately dense aerial mycelium and then turned grey after $4 \mathrm{~d}$ with thick aerial mycelium. The mycelium consisted of smooth, branched, septate and subhyaline hyphae. No conidium was observed under the test conditions employed, including cultivation on water agar (WA) with pine needles or mistletoe twigs for $45 \mathrm{~d}$ or at room temperature with diffused daylight. The optimum temperature for strain growth was $30^{\circ} \mathrm{C}$, and the strain reached $90 \mathrm{~mm}$ in diameter on PDA and synthetic low nutrient agar (SNA) after 48 and $96 \mathrm{~h}$, respectively.

To acquire phylogenetic information on the fungus, the DNA sequence of the internal transcribed spacer (ITS) regions of ME4-2 was amplified and sequenced. The PCR products included approximately 520 base pairs. Unreliable sequence data from the ends of the sequences were excluded and 484 characters (GenBank Accession No. KJ913675) were used during analysis. A phylogenetic tree was constructed (Figure 2) based on the ITS sequences of ME4-2 and closely related strains. ME4-2 formed a distinct branch within the genus Lasiodiplodia and was closely related to L. pseudotheobromae. Molecular analysis indicated that ME4-2 is a new member of the genus Lasiodiplodia. Previous research [28] showed that Lasiodiplodia sp. is one of the more common endophytes found in marketed flowers, consistent with our findings. We note, however, that the use of a single ITS sequence is insufficient to achieve complete analysis. To establish the taxonomic status of the strain with high precision, three or more genes are necessary to construct phylogenetic trees.

\section{Secondary metabolites produced by strain ME4-2 in broth culture}

To characterise Lasiodiplodia sp. ME4-2 further, secondary metabolites produced by the strain cultured in Czapek's broth for $6 \mathrm{~d}$ were isolated and identified. Four aromatic compounds with relatively high concentrations were obtained and identified as cyclo-(Trp-Ala) (1), ICA (2), indole-3-carbaldehyde (3) and mellein (4). An additional trace but detectable compound, namely, 2-phenylethanol (5), was also found using gas chromatograph-mass spectrometry (GC-MS).

Compound 1 was determined as cyclo-(Trp-Ala) (mass spectrum: m/z 256, $[\mathrm{M}-\mathrm{H}]^{-1}$ ) by nuclear magnetic resonance (NMR) analysis and comparison of its date with those reported in the literature [29]. The compound is 


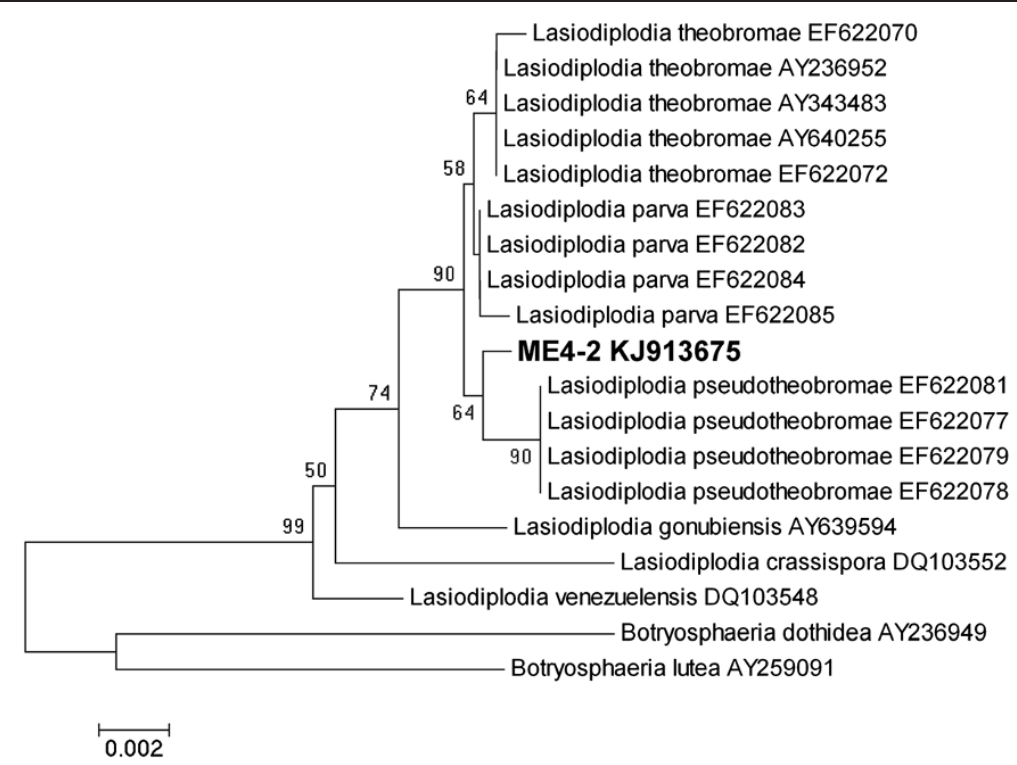

Figure 2 Unrooted neighbour-joining tree for ME4-2 within Lasiodiplodia species. Numbers at nodes indicate bootstrap values (expressed as percentages of 1000 replications); Values lower than $50 \%$ are not indicated. Scale bar $=0.002$ substitutions per nucleotide position.

known to be isolated from many microorganisms and shows weak antioxidant activity [30].

Compounds 2 and 3 were identified as ICA and indole-3-carbaldehyde, respectively, through comparison with authentic samples (Table 1). The molecular structures of the compounds were further confirmed through their NMR spectra. Both compounds are commonly present in microorganisms and plants and present antimicrobial and antitumor activities [31,32]. The biological role of ICA, which is regarded as an inactive auxin (indole-3-acetic acid, IAA) analogue, in plants has long been neglected. Recent studies indicate that ICA may perform important functions in plant basal defence against biotic stress, and has been identified as a mediator of induced resistance in Arabidopsis against plant pathogens [33,34]. Endophytes are known to produce bioactive compounds that protect their plant hosts from various pathogens. However, whether or not ICA is actually produced in the plant and whether or not the compound produced by ME4-2 is beneficial to its host have yet to be determined.

Compound 4 was identified as mellein based on GCMS and NMR data. The GC-MS spectrum of 4 showed a molecular ion peak at $\mathrm{m} / \mathrm{z} 178$, which is identical to that of mellein. The UV, ${ }^{1} \mathrm{H}$ NMR and ${ }^{13} \mathrm{C}$ NMR data of 4 were also consistent with those reported for the known compound $[35,36]$. Whilst mellein has been previously isolated from various fungi, including plant pathogens and endophytes, the present study is the first to report mellein isolation from a floral endophytic fungus. Mellein, originally identified as a phytotoxic compound, is a versatile compound with various biological activities, such as antibacterial, fungicidal, anti-worm and $\mathrm{HCV}$ protease-inhibitory [37]. Interestingly, the compound has been also isolated from various insect secretions as a trail or alarm pheromone [38].

Table $1 \mathrm{GC} / \mathrm{MS}$ analysis of the compounds produced by ME4-2 after 6 days of incubation at $28^{\circ} \mathrm{C}$ in $\mathrm{Czapek}$ 's broth

\begin{tabular}{lllll}
\hline $\mathbf{R}_{\mathbf{t}}(\mathbf{m i n})$ & molecular mass (Da) & Possible compounds & Standards $^{\mathbf{a}}$ & Similarity (\%) $^{\mathbf{b}}$ \\
\hline 8.95 & 122 & 2-phenylethanol & a & 98 \\
13.25 & 117 & Indole & a & 95 \\
17.67 & 178 & Mellein & & 89 \\
22.91 & 145 & Indole-3-carbaldehyde & a & 94 \\
24.80 & 161 & Indole-3-carboxylic acid & a & 94 \\
34.94 & 204 & Tryptophan & a & 90 \\
35.29 & 257 & Cyclo-(Trp-Ala) & & 90 \\
\hline
\end{tabular}

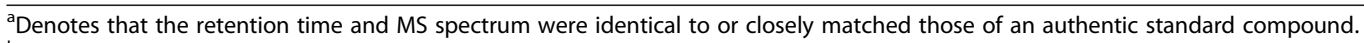

${ }^{b}$ Denotes the similarity between the mass spectrum of a secondary metabolite produced by ME4-2 and the most closely matched compound in the National Institute for Standards and Technology (NIST) database. 
Compound 5 was determined to be 2-phenylethanol through comparison with a commercially available standard (Table 1). The fragmentation pattern of the compound in its GC-MS spectrum as well as its behaviour during high-pressure liquid chromatography (HPLC) were identical to those of synthetic 2-phenylethanol. Compound 5 was a minor secondary metabolite produced by Lasiodiplodia sp. ME4-2 cultured in PDA and Czapek's broth. Supplementing the basic growth medium with precursors can improve the yields of the microbial products [39]. To increase 2-phenylethanol production, ME4-2 was cultured in Czapek's broth supplemented with $6 \mathrm{~g} / \mathrm{L}$ L-phenylalanine, a well-known precursor of 2-phenylethanol. Addition of L-phenylalanine to Czapek's medium significantly increased 2-phenylethanol contents (Figure 3), which reached $226 \mathrm{mg} / \mathrm{L}$. By contrast, a low 2-phenylethanol content of around 7-35 mg/L was obtained when the medium contained yeast extracts, peptone, tryptophan or $\left(\mathrm{NH}_{4}\right)_{2} \mathrm{SO} 4$ as an additional nitrogen source.

2-Phenylethanol, a well-known flavour and fragrance substance with a rose-like odour, naturally occurs in the essential oils of certain flowers, such as rose, narcissi, lilies and jasmine [40]. Natural 2-phenylethanol has also been isolated from several types of fungi, including yeasts, mushrooms and filamentous fungi [41]. It is now generally accepted that some endophytes can produce similar chemical compounds to those produced by their hosts [15]. However, few floral endophytes have been screened for essential oil components, such as 2-phenylethanol. Consumer preference for natural compounds has recently stimulated the search for microorganisms that can produce 2-phenylethanol. Isolation of Lasiodiplodia sp. ME4-2, a potential phenylethanol producer, indicates that flower endophytes may be important resources of natural flavours.

\section{ICA biosynthetic pathway in Lasiodiplodia sp. ME4-2}

ICA is an important intermediate product for pharmaceutical and agricultural industries with an aromatic indole ring [42]. Interestingly, ME4-2 can synthesise ICA without tryptophan, which is believed to be a precursor of ICA. It has been suggested that tryptophan was converted to ICA via IAA in microorganisms [43]. Several holoparasitic dicotyledonous plants, however, can directly metabolise L-tryptophan to indole-3carboxaldehyde, which is further converted to ICA [44]. The ICA biosynthetic pathway in ME4-2 was examined by analysing metabolic intermediates. The GC-MS spectrum of the fungal culture extract showed (Table 1) the presence of a peak at a retention time of $24.80 \mathrm{~min}$, which corresponds well with standard ICA. Peaks with retention times of 13.25, 22.91 and $34.94 \mathrm{~min}$ corresponded to the retention times of authentic indole, indole-3-carbaldehyde and tryptophan, respectively. No IAA was detected in the culture medium. Whilst these results suggest that de novo ICA biosynthesis in ME4-2 may occur via an IAA-independent route, more studies are necessary to confirm this hypothesis.

\section{Conclusion}

In this study, a fungal endophyte Lasiodiplodia sp. ME42 from mistletoe flowers was isolated and identified using molecular characterisation results. Lasiodiplodia sp. ME4-2 is a newly isolated endophyte that can produce several interesting aromatic compounds, including cyclo-(Trp-Ala), ICA, indole-3-carbaldehyde, mellein and 2-phenylethanol, which are valuable compounds for the pharmaceutical and food industries. A pooled analysis of published literature together with our results suggests a close relationship between the strain and its floral host. ICA, a plant cell wall-bound metabolite that could mediate accelerated callose accumulation in

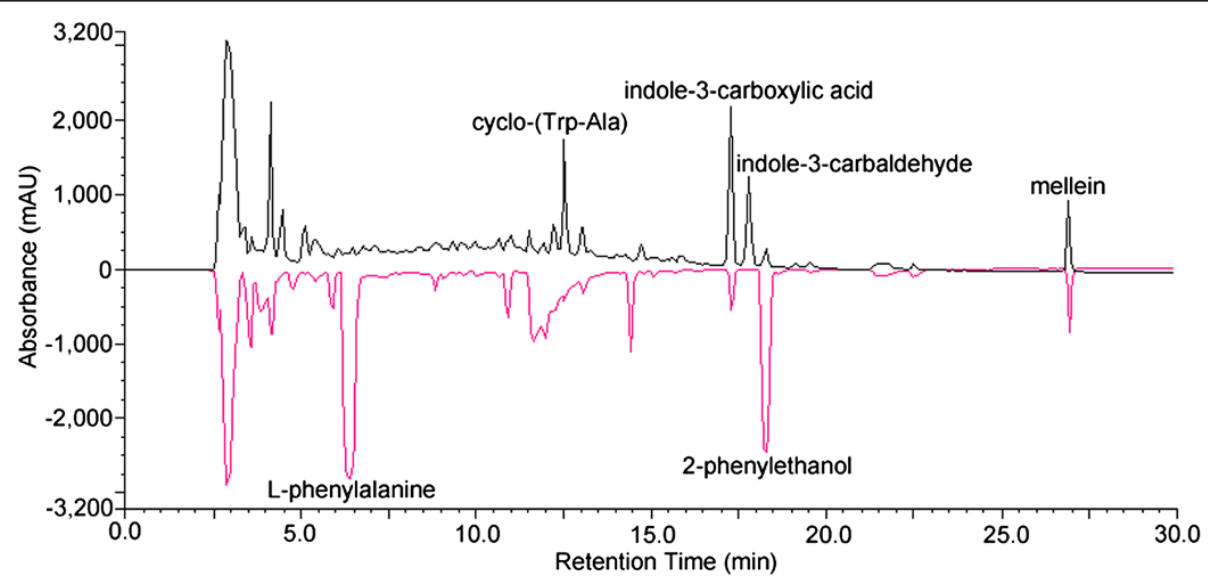

Figure 3 Effect of L-phenylalanine supplementation to Czapek's medium on 2-phenylethanol production. The red and black curve represent for the fermentation supernatant with or without L-phenylalanine $(6 \mathrm{~g} / \mathrm{L})$, respectively. UV absorption was measured at $210 \mathrm{~nm}$. 
response to pathogens, may enhance the host adaptation to various biotic stress factors. Mellein, whether as a phytotoxic compound or an alarm pheromone, may also affect the growth of its host plant. 2-Phenylethanol is a common component of flower essential oils. Although only small amounts of 2-phenylethanol are produced by ME4-2 cultured in synthetic media, production of this compound can be significantly increased by addition of L-phenylalanine to the culture broth. Interestingly, the major route of ICA biosynthesis in Lasiodiplodia sp. ME4-2 does not occur through IAA, which has been considered a precursor of ICA except in several rare cases. The present study introduces a fungal producer of several important aromatic compounds and enriches our knowledge of endophytes.

\section{Methods}

\section{Fungal isolation and storage}

Healthy flowers of the medicinal plant Viscum coloratum were collected from Hangzhou City, Zhejiang Province, China. Samples were placed in sterilised bags and kept on ice during transportation. All flowers were processed within $24 \mathrm{~h}$ of collection. The flowers were thoroughly washed in tap water and cut into small segments (about $1 \mathrm{~cm} \times 1 \mathrm{~cm})$. These segments were sterilised with $75 \%$ ethanol for $30 \mathrm{~s}$ and with $0.1 \%$ mercury dichloride for $1 \mathrm{~min}$ and then rinsed six times with sterile distilled water. Sterilised segments were placed on PDA and cultured at $28^{\circ} \mathrm{C}$ for $2-14 \mathrm{~d}$ to allow the growth of endophytic fungi. Individual colonies were then hyphal tipped and transferred to fresh PDA. Pure isolates were maintained on PDA at $28^{\circ} \mathrm{C}$ and stored at $5^{\circ} \mathrm{C}$.

\section{Morphology characteristics}

Morphological observations of the colonies were based on the isolated strain (ME4-2) grown on PDA and Czapek's medium $\left(3.0 \mathrm{~g} \mathrm{NaNO}, 1.0 \mathrm{~g} \mathrm{~K}_{2} \mathrm{HPO}_{4}, 0.5 \mathrm{~g}\right.$ $\mathrm{MgSO}_{4} \cdot 7 \mathrm{H}_{2} \mathrm{O}, 0.5 \mathrm{~g} \mathrm{KCl}, 0.01 \mathrm{~g} \mathrm{FeSO}_{4} \cdot 7 \mathrm{H}_{2} \mathrm{O}, 30.0 \mathrm{~g}$ sucrose, $20.0 \mathrm{~g}$ agar, and $1 \mathrm{~L}$ distilled water; $\mathrm{pH}$ 6.8) at $28^{\circ} \mathrm{C}$. Microscopic observations of morphological features were performed using an Olympus BX51 microscope and DP71 digital camera. To induce sporulation, isolated ME4-2 was either grown on 2\% WA with sterilised pine needles or mistletoe twigs placed in the medium incubated at $25^{\circ} \mathrm{C}$ in the dark or cultured at room temperature with diffused daylight [45]. Growth rates on PDA and SNA (1.0 $\mathrm{g} \mathrm{KH}_{2} \mathrm{PO}_{4}, 1.0 \mathrm{~g} \mathrm{KNO}_{3}, 0.5 \mathrm{~g} \mathrm{MgSO}_{4} \cdot 7 \mathrm{H}_{2} \mathrm{O}, 0.5 \mathrm{~g}$ $\mathrm{KCl}, 0.2 \mathrm{~g}$ glucose, $0.2 \mathrm{~g}$ sucrose, $1.0 \mathrm{~L}$ distilled water and 20.0 g agar) at $20,25,30,35$ and $40^{\circ} \mathrm{C}$ were determined using the method described by Chaverri et al. [46].

\section{DNA extraction, PCR amplification and sequencing}

Isolated ME4-2 was grown in PDA for $4 \mathrm{~d}$ at $28^{\circ} \mathrm{C}$. Genomic DNA was extracted from the mycelium according to the cetyltrimethylammonium bromide method [47]. The nuclear 5.8S ribosomal RNA gene and its flanking ITS regions were amplified using two universal primers, ITS1 and ITS4 [48]. The PCR products were separated by electrophoresis in 1\% agarose gels and purified using a QIAquick gel exaction kit (Qiagen). The purified PCR products were then sequenced in both directions using the same primers used for PCR reactions. Sequence reactions were run on a Model 3730 automated capillary DNA sequencer (Applied Biosystems, Foster City, USA). The ITS sequence of strain ME4-2 was deposited in GenBank under the accession number KJ913675.

\section{Phylogenetic analysis}

The ITS sequence of the endophytic fungus was analysed along with closely related sequences retrieved from GenBank using BLAST [49]. Sequences were aligned with Clustal W [50] and manually edited. A phylogenetic tree was constructed using the neighbour-joining method [51] with MEGA version 4.0 [52]. Tree topologies were evaluated using bootstrap analysis based on 1000 resamplings.

\section{Fermentation and compound isolation}

ME4-2 was grown in $2 \mathrm{~L}$ Erlenmeyer flasks containing $800 \mathrm{~mL}$ of Czapek's broth medium. Fermentation was conducted on a rotary shaker $(120 \mathrm{rpm})$ at $28^{\circ} \mathrm{C}$ for $6 \mathrm{~d}$. The culture broth $(10 \mathrm{~L})$ was filtered twice through six layers of conventional gauze, and the cell-free supernatant was loaded onto an AB-8 macroporous absorption resin column pre-equilibrated with distilled water. The column was washed with distilled water and eluted with $25 \%$ and $75 \%(\mathrm{v} / \mathrm{v})$ methanol. The $75 \%$ methanol fraction was pooled and concentrated at $50^{\circ} \mathrm{C}$ using a rotary evaporator. The concentrated solution was centrifuged at $6000 \mathrm{rpm}$ for $30 \mathrm{~min}$, and the supernatant was transferred to a $\mathrm{C}_{18}$ SPE column (Hardwee, Germany). The column was washed with three bed volumes of distilled water followed by three bed volumes of a methanol/water mixture $(20: 80, \mathrm{v} / \mathrm{v})$. The fraction eluted from the SPE column with a methanol/water mixture (60:40, v/v) was further concentrated and purified using semi-preparative HPLC on a Venusil XBP $\mathrm{C}_{18}(5 \mu \mathrm{m}$, $250 \times 10 \mathrm{~mm}$ ) column. HPLC was performed on a Dionex Ultimate 3000 HPLC System (Thermo Fisher Scientific, Waltham, USA) with a diode-array UV/VIS detector. The mobile phase was composed of an acetonitrile-water (0.05\% formic acid) mixture and programmed using a linear gradient from $5 \%$ to $65 \%$ over $30 \mathrm{~min}$. The UV detector was set to 210, 230, 260 and $280 \mathrm{~nm}$, and the flow rate was $5 \mathrm{~mL} / \mathrm{min}$.

\section{Spectroscopic measurements}

NMR spectra were recorded using an AVANCE DMX-600 spectrometer (Bruker, Karlsruhe, Germany) in dimethyl 
sulfoxide-d6 (1, 2 and 4) or acetone-d6 (3) at $27^{\circ} \mathrm{C}$. Electrospray ionisation mass spectra were recorded in negative ion mode on a Thermo Finnigan LCQ mass spectrometer (Thermo Electron Corp., San Jose, USA).

\section{GC analyses}

About $100 \mathrm{~mL}$ of culture broth (Czapek) was centrifuged at $10000 \mathrm{~g}$ for $20 \mathrm{~min}$. The supernatant was extracted with $100 \mathrm{~mL}$ of chloroform, and the organic phase was concentrated to approximately $10 \mathrm{~mL}$ before GC analysis using a Focus GC-MS system (Thermo Scientific) equipped with an Rtx-5MS capillary column $(30 \mathrm{~m} \times$ $0.25 \mathrm{~mm}, 0.25 \mu \mathrm{m})$. The injector temperature was $250^{\circ} \mathrm{C}$, and the flow rate of the helium carrier gas was $1.23 \mathrm{~mL} / \mathrm{min}$. The column temperature was maintained at $60^{\circ} \mathrm{C}$ for $3 \mathrm{~min}$, raised to $180^{\circ} \mathrm{C}$ at $8^{\circ} \mathrm{C} / \mathrm{min}$, maintained at $180^{\circ} \mathrm{C}$ for $4 \mathrm{~min}$, ramped to $300^{\circ} \mathrm{C}$ at $10^{\circ} \mathrm{C} / \mathrm{min}$ and finally held for $5 \mathrm{~min}$ at $300^{\circ} \mathrm{C}$. The data acquisition rate was $100 \mathrm{scans} / \mathrm{s}$, and data were acquired over a mass range of $40-650 \mathrm{~m} / \mathrm{z}$. Compounds were tentatively identified by comparing their mass spectra with those available in the National Institute for Standards and Technology mass spectral library.

\section{Determination of the effect of nitrogen sources on 2- phenylethanol production}

The growth medium (Czapek's broth) was supplemented with different nitrogen sources to improve 2-phenylethanol production, and the effects of these sources on 2phenylethanol production were studied. Culture supernatants were filtered through $0.2 \mu \mathrm{m}$ filters prior to analysis. 2-Phenylethanol in the aqueous phase was analysed by HPLC on a Dionex C18 reversed-phase column $(250 \times 4.6 \mathrm{~mm}, 5 \mu \mathrm{m})$ over a linear gradient of $10 \%$ to $65 \%$ acetonitrile flowing at a rate of $1 \mathrm{~mL} / \mathrm{min}$ for $30 \mathrm{~min}$ and UV detection at $210 \mathrm{~nm}$.

\section{Abbreviations}

ITS: Internal transcribed spacer; ICA: Indole-3-carboxylic acid; IAA: Indole-3acetic acid; GC-MS: Gas chromatograph-mass spectrometer; PDA: Potato dextrose agar; WA: Water agar; NMR: Nuclear magnetic resonance; ESI-MS: Electrospray ionization-mass spectra; NIST: National institute for standards and technology; HPLC: High-pressure liquid chromatography; SNA: Synthetic low nutrient agar.

\section{Competing interests}

The authors declared that they no competing interests.

\section{Authors' contributions}

CDQ was responsible for designing the study, and wrote the manuscript. YHF and FSJ carried out the isolation and identification of the strain. CDQ, YHF and ZHX carried out the isolation and purification of secondary metabolites. DQC, BD and CXG helped to revise the manuscript. ZSD was responsible for the integrity of the work as a whole. All authors read and approved the final manuscript.

\section{Acknowledgements}

We thank Xing-Hong Ding, Analysis and Testing Centre, Zhejiang Chinese Medical University, for providing GC-MS and NMR measurements. We gratefully acknowledge Zha-Jun Zhan, College of Pharmaceutical Science, Zhejiang University of Technology, for NMR data analysis. This work was partially supported by Talents Special Research Funds of Zhejiang Chinese Medical University (No. 112953C00401/027)

Received: 9 June 2014 Accepted: 13 November 2014

Published online: 30 November 2014

\section{References}

1. Rodriguez R, White J Jr, Arnold A, Redman R: Fungal endophytes: diversity and functional roles. New Phytol 2009, 182(2):314-330

2. Tan R, Zou W: Endophytes: a rich source of functional metabolites. Nat Prod Rep 2001, 18(4):448-459.

3. Siegel MR, Schardl CL, Phillips TD: Incidence and compatibility of nonclavicipitaceous fungal endophytes in Festuca and Lolium grass species. Mycologia 1995, 87(2):196-202.

4. Schardl CL, Leuchtmann A, Spiering MJ: Symbioses of grasses with seedborne fungal endophytes. Annu Rev Plant Biol 2004, 55:315-340.

5. Rosenblueth M, Martínez-Romero E: Bacterial endophytes and their interactions with hosts. Mol Plant Microbe In 2006, 19(8):827-837.

6. Tanaka A, Tapper BA, Popay A, Parker EJ, Scott B: A symbiosis expressed non-ribosomal peptide synthetase from a mutualistic fungal endophyte of perennial ryegrass confers protection to the symbiotum from insect herbivory. Mol Microbiol 2005, 57(4):1036-1050.

7. Pirttilä AM, Joensuu P, Pospiech H, Jalonen J, Hohtola A: Bud endophytes of Scots pine produce adenine derivatives and other compounds that affect morphology and mitigate browning of callus cultures. Physiol Plantarum 2004, 121(2):305-312.

8. Tudzynski B: Fungal phytohormones in pathogenic and mutualistic associations. Plant Relationships 1997, 5:167-184.

9. Stierle A, Strobel G, Stierle D: Taxol and taxane production by Taxomyces andreanae, an endophytic fungus of Pacific yew. Science 1993, 260(5105):214-216.

10. Puri SC, Verma V, Amna T, Qazi GN, Spiteller M: An endophytic fungus from Nothapodytes foetida that produces camptothecin. J Nat Prod 2005, 68(12):1717-1719.

11. Findlay JA, Buthelezi S, Lavoie R, Peña-Rodriguez L, Miller JD: Bioactive isocoumarins and related metabolites from conifer endophytes. J Nat Prod 1995, 58(11):1759-1766.

12. Eyberger AL, Dondapati R, Porter JR: Endophyte fungal isolates from Podophyllum peltatum produce podophyllotoxin. I Nat Prod 2006, 69(8):1121-1124.

13. Alvin A, Miller Kl, Neilan BA: Exploring the potential of endophytes from medicinal plants as sources of antimycobacterial compounds. Microbiol Res 2014, 169(7):483-495.

14. Kharwar RN, Mishra A, Gond SK, Stierle A, Stierle D: Anticancer compounds derived from fungal endophytes: their importance and future challenges. Nat Prod Rep 2011, 28(7):1208-1228.

15. Aly AH, Debbab A, Kjer J, Proksch P: Fungal endophytes from higher plants: a prolific source of phytochemicals and other bioactive natural products. Fungal Divers 2010, 41(1):1-16.

16. Heinig U, Scholz S, Jennewein S: Getting to the bottom of Taxol biosynthesis by fungi. Fungal Divers 2013, 60(1):161-170.

17. Miller Kl, Qing C, Sze DM-Y, Roufogalis BD, Neilan BA: Culturable endophytes of medicinal plants and the genetic basis for their bioactivity. Microbial Ecol 2012, 64(2):431-449.

18. Schulz B, Boyle C, Draeger S, Römmert A-K, Krohn K: Endophytic fungi: a source of novel biologically active secondary metabolites. Mycol Res 2002, 106(9):996-1004

19. Gunatilaka AL: Natural products from plant-associated microorganisms: distribution, structural diversity, bioactivity, and implications of their occurrence. J Nat Prod 2006, 69(3):509-526.

20. Kusari S, Spiteller M: Are we ready for industrial production of bioactive plant secondary metabolites utilizing endophytes? Nat Prod Rep 2011, 28(7):1203-1207.

21. Suryanarayanan TS, Thirunavukkarasu N, Govindarajulu MB, Gopalan V: Fungal endophytes: an untapped source of biocatalysts. Fungal Divers 2012, 54(1):19-30. 
22. Xiao YY, Weng JY, Fan JS: Mistletoe on ancient and Modern. Strait Pharmaceutical journal 2008, 20(2):45-47.

23. Hwang TL, Leu YL, Kao SH, Tang MC, Chang HL: Viscolin, a new chalcone from Viscum coloratum, inhibits human neutrophil superoxide anion and elastase release via a cAMP-dependent pathway. Free Radical Bio Med 2006, 41(9):1433-1441.

24. Kong DY, Li H, Luo S, Lei XH: Studies on the chemical components of Viscum coloratum. VI. Chirality of the acyl group of viscumneoside IV. Yao Xue Xue Bao 1990, 25(5):349-352.

25. Chen BN, Yang GE, Li JK, Du HJ, Li QS, Zhang ZM: Cytotoxic constituents from Viscum coloratum. Chem Nat Compd 2009, 45(4):547-549.

26. Peršoh D, Melcher M, Flessa F, Rambold G: First fungal community analyses of endophytic ascomycetes associated with Viscum album ssp. austriacum and its host Pinus sylvestris. Fungal Biol 2010, 114(7):585-596.

27. Peršoh D: Factors shaping community structure of endophytic fungi-evidence from the Pinus-Viscum-system. Fungal Divers 2013, 60(1):55-69.

28. Kannan K, Madhankumar D, Prakash NU, Muthezilan R, Jamuna G, Parthasarathy N, Bhuvaneshwari S: Fungal endophytes: a preliminary report from marketed flowers. Intl J App/ Biol 2011, 2(1):14-18.

29. Li Y, Sun KL, Wang Y, Fu P, Liu PP, Wang C, Zhu WM: A cytotoxic pyrrolidinoindoline diketopiperazine dimer from the algal fungus Eurotium herbariorum HT-2. Chinese Chem Lett 2013, 24:1049-1052.

30. Tian SZ, Pu X, Luo G, Zhao LX, Xu LH, Li WJ, Luo Y: Isolation and characterization of new p-terphenyls with antifungal, antibacterial, and antioxidant activities from halophilic actinomycete Nocardiopsis gilva YIM 90087. J Agr Food Chem 2013, 61(12):3006-3012.

31. Anderton MJ, Manson MM, Verschoyle RD, Gescher A, Lamb JH, Farmer PB, Steward WP, Williams ML: Pharmacokinetics and tissue disposition of indole-3-carbinol and its acid condensation products after oral administration to mice. Clin Cancer Res 2004, 10(15):5233-5241.

32. Yue Q, Miller CJ, White JF, Richardson MD: Isolation and characterization of fungal inhibitors from Epichloë festucae. J Agr Food Chem 2000, 48(10):4687-4692

33. Forcat S, Bennett M, Grant M, Mansfield JW: Rapid linkage of indole carboxylic acid to the plant cell wall identified as a component of basal defence in Arabidopsis against hrp mutant bacteria. Phytochemistry 2010, 71(8):870-876

34. Gamir J, Pastor V, Cerezo M, Flors V: Identification of indole-3-carboxylic acid as mediator of priming against Plectosphaerella cucumerina. Plan Physiol Bioch 2012, 61:169-179.

35. Dimitriadis C, Gill M, Harte MF: The first stereospecific approach to both enantiomers of mellein. Tetrahedron-Asymmetry 1997, 8(13):2153-2158.

36. Venkatasubbaiah P, Chilton WS: Phytotoxins of Botryosphaeria obtusa. J Nat Prod 1990, 53(6):1628-1630.

37. Sun $H_{1}, H o C L$, Ding F, Soehano I, Liu XW, Liang ZX: Synthesis of (R)-mellein by a partially reducing iterative polyketide synthase. J Am Chem Soc 2012, 134(29):11924-11927

38. Kalinová B, Kindl J, Jiros P, Zácek P, Vasícková S, Budesínský M, Valterová I: Composition and electrophysiological activity of constituents identified in male wing gland secretion of the bumblebee parasite Aphomia sociella. J Nat Prod 2008, 72(1):8-13.

39. Thiericke $R$, Rohr J: Biological variation of microbial metabolites by precursor-directed biosynthesis. Nat Prod Rep 1993, 10(3):265-289.

40. Hua D, Xu P: Recent advances in biotechnological production of 2-phenylethanol. Biotechnol Adv 2011, 29(6):654-660

41. Lomascolo A, Lesage-Meessen L, Haon M, Navarro D, Antona C, Faulds C Marcel A: Evaluation of the potential of Aspergillus niger species for the bioconversion of L-phenylalanine into 2-phenylethanol. World J Microb Biot 2001, 17(1):99-102.

42. Melkonyan FS, Karchava AV, Yurovskaya MA: Synthesis of N-substituted indole-3-carboxylic acid derivatives via $\mathrm{Cu}$ (I)-catalyzed intramolecular amination of aryl bromides. J Org Chem 2008, 73(11):4275-4278.

43. Davis PJ, Gustafson ME, Rosazza JP: Formation of indole-3-carboxylic acid by Chromobacterium violaceum. J Bacteriol 1976, 126(1):544.

44. Magnus V, Simaga S, IskriC S, Kveder S: Metabolism of tryptophan, indole-3-acetic acid, and related compounds in parasitic plants from the genus Orobanche. Plant Physiol 1982, 69(4):853-858.

45. Alves A, Crous P, Correia A, Phillips A: Morphological and molecular data reveal cryptic speciation in Lasiodiplodia theobromae. Fungal Divers 2008, 28(1):1-13.
46. Chaverri P, Gazis RO, Samuels GJ: Trichoderma amazonicum, a new endophytic species on Hevea brasiliensis and $H$. guianensis from the Amazon basin. Mycologia 2011, 103(1):139-151.

47. Stewart CN Jr, Via LE: A rapid CTAB DNA isolation technique useful for RAPD fingerprinting and other PCR applications. Biotechniques 1993, 14(5):748-750

48. White TJ, Bruns T, Lee S, Taylor J: Amplification and direct sequencing of fungal ribosomal RNA genes for phylogenetics. In PCR Protocols: A Guide to Methods and Applications. Edited by Innis MA, Gelfand DH, Sninsky JJ, White TJ. New York: Academic Press Inc; 1990:315-322.

49. Altschul SF, Gish W, Miller W, Myers EW, Lipman DJ: Basic local alignment search tool. J Mol Biol 1990, 215(3):403-410.

50. Thompson JD, Higgins DG, Gibson TJ: CLUSTAL W: improving the sensitivity of progressive multiple sequence alignment through sequence weighting, position-specific gap penalties and weight matrix choice. Nucleic Acids Res 1994, 22(22):4673-4680.

51. Saitou N, Nei M: The neighbor-joining method: a new method for reconstructing phylogenetic trees. Mol Biol Evol 1987, 4(4):406-425.

52. Tamura K, Dudley J, Nei M, Kumar S: MEGA4: molecular evolutionary genetics analysis (MEGA) software version 4.0. Mol Biol Evol 2007, 24(8):1596-1599.

doi:10.1186/s12866-014-0297-0

Cite this article as: Qian et al:: Lasiodiplodia sp. ME4-2, an endophytic fungus from the floral parts of Viscum coloratum, produces indole-3carboxylic acid and other aromatic metabolites. BMC Microbiology 2014 14:297

\section{Submit your next manuscript to BioMed Central and take full advantage of:}

- Convenient online submission

- Thorough peer review

- No space constraints or color figure charges

- Immediate publication on acceptance

- Inclusion in PubMed, CAS, Scopus and Google Scholar

- Research which is freely available for redistribution

Submit your manuscript at www.biomedcentral.com/submit
C Biomed Central 